REVIEW

\title{
Acquired non-type 1 diabetes in childhood: subtypes, diagnosis, and management
}

\author{
J R Porter, T G Barrett
}

Arch Dis Child 2004;89:1138-1144. doi: 10.1136/adc.2003.036608

Over the past 30 years it has become apparent that not all diabetes presenting in childhood is autoimmune type 1 . Increasingly type 2 diabetes, maturity onset diabetes of the young, iatrogenic diabetes, and rare syndromic forms of diabetes such as Wolfram's syndrome have been identified in children. This review is aimed at the general paediatrician looking after children with diabetes, and aims to provide an algorithm for assessment, investigation, and suggested management for the newly diagnosed child with suspected non-type 1 diabetes. This article will also be relevant to the child with atypical diabetes - that is, on low insulin doses outside the honeymoon period.

See end of article for authors' affiliations

Correspondence to: Dr T G Barrett, Consultant Paediatric Endocrinologist, Department of Diabetes, Birmingham Children's Hospital, Steelhouse Lane Birmingham B4 6NH, UK t.g.barrett@bham.ac.uk

Accepted 17 April 2004
D iabetes is the third most common chronic disease of childhood. ${ }^{1}$ Type 1, or autoimmune diabetes accounts for about $99 \%$ of cases. Type 1 diabetes is characterised by $\beta$ cell destruction, an autoimmune pathological process, and absolute insulin requirement. ${ }^{2}$ Over the past 30 years it has been recognised that not all diabetes in childhood is type 1. Diabetes syndromes such as neonatal diabetes ${ }^{3}$ and Wolfram syndrome have been described; ${ }^{4}$ genetic forms of diabetes such as maturity onset diabetes of the young have been defined; ${ }^{5}$ and more recently both iatrogenic and type 2 diabetes have been noted in childhood. ${ }^{67}$ These subtypes of diabetes are rare; in 2000 a UK national survey of clinicians looking after children with diabetes found only $0.7 \%$ of children with diabetes had non-type 1 diabetes, although this is likely to be an underestimate (table 1). ${ }^{8}$ These patients are important because they cause diagnostic uncertainty and often need different management. This review will discuss non-type 1 diabetes in childhood, and suggest a flow chart for diagnosis and treatment. Neonatal diabetes is a specialist management problem and beyond the scope of this article.

\section{DIAGNOSTIC SUBGROUPS}

Diabetes may present symptomatically or be an incidental finding. The World Health Organisation has laid down criteria for diagnosis of diabetes: a venous plasma glucose $\geqslant 7 \mathrm{mmol} / \mathrm{l}$ fasted or $\geqslant 11.1 \mathrm{mmol} / \mathrm{l}$ unfasted on more than one occasion. ${ }^{2}$ Diabetes in an asymptomatic child should never be diagnosed on a single test of plasma glucose, but a single measurement in excess of the established values in a child with symptoms of polyuria, polydipsia, and weight loss is sufficient for diagnosis. ${ }^{2}$
This review considers children at diagnosis in three categories: those that are unwell or have ketonuria, those that are well with mild or absent symptoms, and those that have features of other chronic disorders or factors predisposing to diabetes (diabetes and disorder). These three groups are outlined in fig 1.

\section{THE UNWELL OR KETOTIC CHILD WITH NEWLY DIAGNOSED DIABETES (FIG 1, BOX A)}

The unwell or ketotic child must be assumed to have type 1 diabetes unless there is good evidence otherwise. Ketonuria is present only in a minority of patients presenting with type 2 diabetes. ${ }^{9}$ Obesity is suggestive of type 2 diabetes, but some children with type 1 diabetes are also obese at presentation. This reflects the increasing prevalence of obesity in the general population rather than a change in the pathophysiology of type 1 diabetes. ${ }^{10}$ We recommend that unwell or ketotic children be insulin treated at presentation. The diagnosis and management can then be reviewed subsequently if there are atypical features to the diabetes. Features such as low insulin requirement outside the honeymoon period (that is, $<0.5$ units $/ \mathrm{kg}>3$ years after diagnosis), ${ }^{11}$ no subsequent ketonuria at times of illness, strong family history of non-type 1 diabetes, and development of auditory, ophthalmic, or renal abnormalities, should prompt consideration of other diabetes subtypes. Measurement of pancreatic antibody levels is useful in these cases. The common antibodies tested for in diabetes are those to glutamic acid decarboxylase-65 (GAD-65), tyrosine phosphatase (IA- $2 \alpha$ ), and the islet cell (ICA). Antibodies to IA- $2 \alpha$ are present in $68.2-79 \%$, GAD- 65 in $25-$ $76 \%$, and ICA in $80.5-89.9 \%$ of paediatric white type 1 patients at diagnosis, ${ }^{12}{ }^{13}$ although absence of antibodies does not exclude type 1 diabetes. African-Americans and Asian-Indians with type 1 diabetes seem to have a lower prevalence of GAD-65 antibodies, ${ }^{14}{ }^{15}$ and there are low antibody levels in normal populations. ${ }^{16}$ We recommend measuring GAD-65 antibodies to confirm autoimmune diabetes in children where there is diagnostic doubt.

Abbreviations: CFRD, cystic fibrosis related diabetes; GAD-65, glutamic acid decarboxylase-65; HNF- $1 \alpha$, hepatocyte nuclear factor $1 \alpha$; MODY, maturity onset diabetes of the young; OMIM, Online Mendelian Inheritance in Man (database); PCOS, polycystic ovarian syndrome; TRMA, thiamine responsive megaloblastic anaemia 
Table 1 Findings of the 2000 UK national survey of diabetes in childhood ${ }^{8}$

\begin{tabular}{lcc}
\hline Type of diabetes & No. patients & $\%$ \\
\hline Type 1 & 15143 & 99 \\
Type 2 & 24 & 0.16 \\
MODY & 17 & 0.11 \\
Cystic fibrosis & 8 & 0.05 \\
Prader-Willi & 4 & 0.03 \\
Wolfram & 5 & 0.03 \\
latrogenic & 6 & 0.04 \\
Neonatal diabetes & 3 & 0.02 \\
Pancreatectomy & 3 & 0.02 \\
Down's & 2 & 0.01 \\
Others/unclassified & 40 & 0.26 \\
\hline
\end{tabular}

\section{THE WELL CHILD WITH NEWLY DIAGNOSED} DIABETES (FIG 1, BOX B)

A well child with hyperglycaemia is likely to have one of four diagnoses: type 1 diabetes (although it is rare to have children with type 1 diabetes present with hyperglycaemia and total lack of ketones); type 2 diabetes; maturity onset diabetes of the young (MODY); or autoimmune diabetes with slow onset.

\section{Type 2 diabetes}

Type 2 diabetes is characterised by insulin resistance and defective insulin secretion. ${ }^{2}$ Incidence figures for type 2 diabetes vary widely worldwide. ${ }^{17}$ We propose that when making a diagnosis of type 2 diabetes there should be evidence of insulin resistance. ${ }^{2}$ The American Heart Association has suggested that a practical measure of hyperinsulinaemia is the fasting insulin level $(<15 \mathrm{mU} / \mathrm{l}$ (104 pmol/l), normal; 15-20 mU/l (104-139 pmol/l), borderline; >20 mU/l (139 pmol/l), high). ${ }^{18}$ Type 2 diabetes in children was first noted in the UK in $2000 .^{7}$ Initial cases described were all female, overweight, and of Asian or Arabic origin. More recently type 2 diabetes has been seen in white children. ${ }^{19}$

Patients with type 2 diabetes are likely to be overweight or obese using international obesity task force (IOTF) cut-offs, ${ }^{20}$ with a tendency towards central fat deposition as measured by waist circumference, have a family history of diabetes, and have the metabolic syndrome (acanthosis nigricans, polycystic ovarian disease, hyperlipidaemia, hypertension, and fatty infiltration of the liver). ${ }^{17}$ Other suggestive features include a family history of insulin resistance (hypertension, abnormal lipids, polycystic ovary syndrome), lack of GAD-65 antibodies, and lack of ketonuria. ${ }^{217}$ A minority of children with apparent type 2 diabetes will have autoantibodies; ${ }^{21}$ these patients are likely to require insulin soon after diagnosis, and may represent a latent autoimmune process. ${ }^{22}$ The UK national survey found that Pakistani children made up $21 \%$ of children with type 2 but only $2.2 \%$ of the UK child population, and Bangladeshi children were also overrepresented. ${ }^{823}$

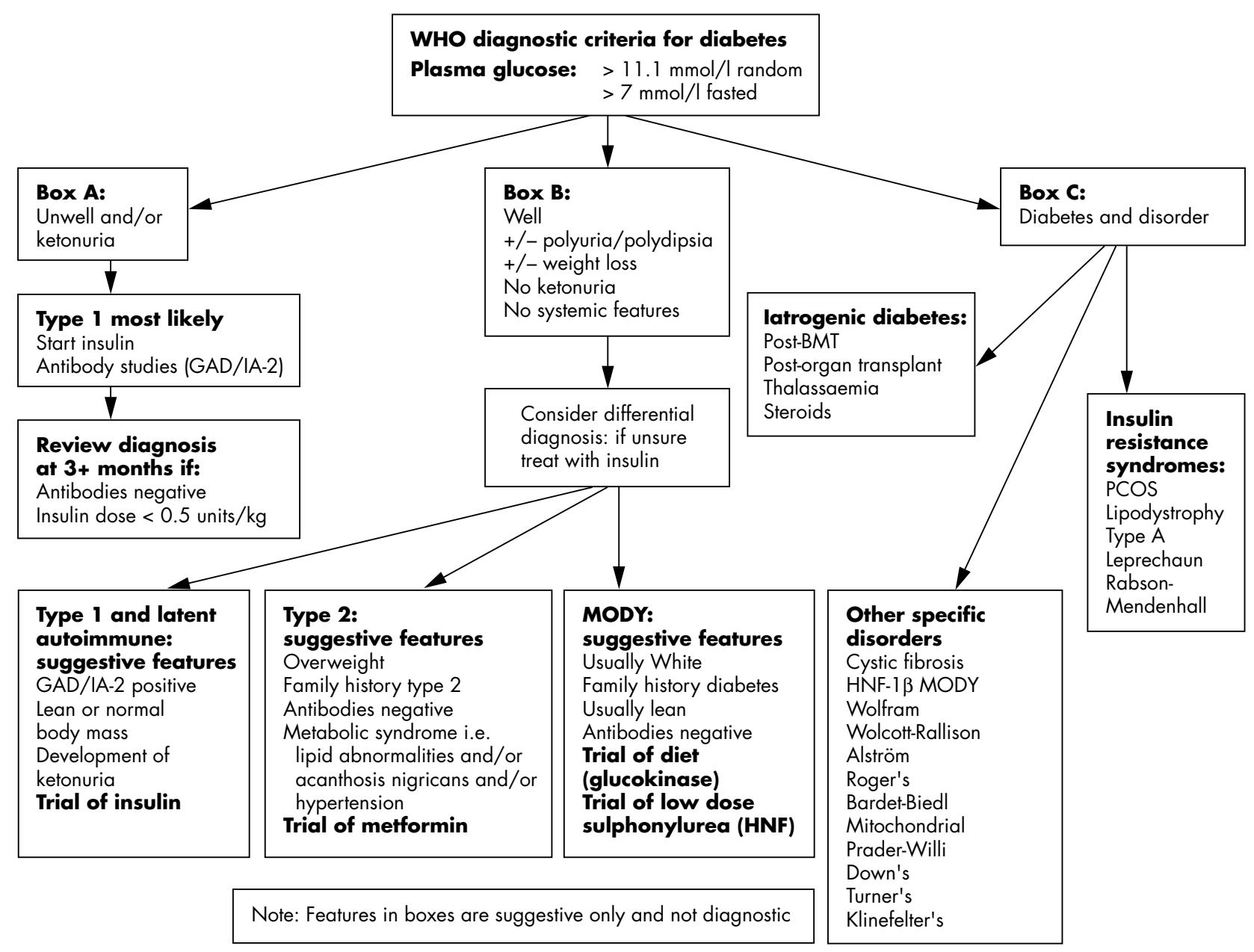

Figure 1 The presentations of acquired childhood diabetes. 
Type 2 diabetes is a disorder of both $\beta$ cell function and insulin sensitivity; ${ }^{21} \beta$ cell function worsens with duration of diabetes leading to insulin dependence. Insulin resistance is related to body weight in both children ${ }^{24}$ and adults, and obesity (particularly deposition of visceral fat) has been linked to type 2 diabetes worldwide. ${ }^{21}$ Ethnic groups especially susceptible to type 2 diabetes have been shown to have greater innate insulin resistance. ${ }^{17} 25$

Children and young people with type 2 diabetes have a greater risk of early retinopathy and nephropathy than those with type 1 diabetes. ${ }^{26}{ }^{27}$ The United Kingdom Prospective Diabetes Study (UKPDS) showed that aggressive treatment of hyperglycaemia can reduce complications. ${ }^{28}$ The American Diabetes Association has published guidelines on treatment of type 2 diabetes in childhood. ${ }^{17}$ Exercise promotion and advice from a paediatric dietician should complement medical management. Drugs used in type 2 diabetes in adults fall into five groups: biguanides, sulphonylureas, thiazolidinediones, nataglinide and repaglinide, and glucosidase inhibitors. None of these drugs are licensed in childhood; however metformin, a biguanide, has been subject to a randomised control trial in adolescents, ${ }^{29}$ and is being used by many clinicians as a first treatment in overweight children with type 2 diabetes. Metformin improves insulin sensitivity and is not associated with hypoglycaemia or weight gain. Side effects include gastrointestinal upset, nausea, and vomiting, and are dose dependent. We start patients on a low dose of metformin (500 mg once daily) and increase this to the maximum tolerated dose. Metformin is contraindicated in patients with renal impairment, and increases fertility in obese girls, so contraceptive advice should be given on commencement.

Hypertension, hyperlipidaemia, and proteinuria should be sought in children with type 2 diabetes and managed aggressively in conjunction with colleagues from other disciplines.

\section{Maturity onset diabetes of the young}

Maturity onset diabetes of the young (MODY) comprises a heterogeneous group of disorders caused by defects in single genes. MODY is characterised by $\beta$ cell dysfunction, young onset $\left(<25\right.$ years), and autosomal dominant inheritance, ${ }^{30}$ and should be considered in non-obese patients with diabetes developing before 25 years of age and a two or three generation history of diabetes in one side of the family. MODY accounted for $15 \%$ of all non-type 1 diabetes in the BSPED survey. ${ }^{8}$

The first MODY gene was found in 1992, ${ }^{5}$ and there are now six known genes in which defects have been shown to cause MODY. ${ }^{31}$ These genes encode for glucokinase, which acts as a glucose sensor and five transcription factors (HNF$1 \alpha$, HNF- $1 \beta$, HNF-4 $\alpha$, IPF-1, and NEURO-D1). Transcription factors are proteins that bind to promoter regions of genes and activate transcription into messenger RNA. They initiate the production of proteins which are important in the development of the pancreas. ${ }^{32}$ Each genotype produces a unique phenotype. ${ }^{31}{ }^{33}$ In the UK hepatocyte nuclear factor $1 \alpha$ (HNF- $1 \alpha$ ) accounts for $63 \%$ of MODY, glucokinase $20 \%$, and other known genes $<5 \%$; $^{33} 15-20 \%$ of MODY patients do not have a known MODY mutation and are termed MODY X. ${ }^{31} 33$

Heterozygous glucokinase mutations produce mild fasting hyperglycaemia $(5.5-8 \mathrm{mmol} / \mathrm{l})$. $^{34}$ Patients may be diagnosed co-incidentally, and so may present at any age. Homozygous glucokinase defects are a rare cause of permanent neonatal diabetes. ${ }^{35}$ HNF- $1 \alpha$ mutation carriers usually have normal blood glucose levels until the teenage years when diabetes presents. If a child with an HNF-1 $\alpha$ mutation is born to a mother who is diabetic they may present with diabetes considerably earlier. ${ }^{36}{ }^{37}$ Patients with glucokinase mutations have glucose values that alter little with age, they have a low risk of complications, and probably do not need long term follow up. In contrast HNF-l $\alpha$ patients have an inexorable $\beta$ cell impairment; the progressive nature of the diabetes means that many patients will eventually require insulin and are at risk of microvascular complications. ${ }^{33}$ Both glucokinase and HNF- $l \alpha$ patients may respond to diet, and HNF- $1 \alpha$ patients are particularly sensitive to sulphonylureas. ${ }^{38}$ Patients with HNF- $1 \alpha$ may be initially managed on diet alone; low dose sulphonylurea (for example, gliclazide $20 \mathrm{mg}$ once daily) can be added when HbAlc levels rise.

Patients with HNF-1 $\beta$ mutations have associated renal cystic disease. This can vary from single kidney involvement to severe urogenital disease. Renal disease usually precedes the development of diabetes. ${ }^{39}$

MODY patients, and genetic testing can be discussed with the MODY diagnostic centre at Peninsula Medical School Exeter (see appendix).

\section{Latent autoimmune diabetes}

Latent autoimmune diabetes is the term used for patients with antibodies consistent with type 1 diabetes, but diabetes that behaves initially as non-insulin requiring. This is generally considered to be an adult disease, but there is evidence to suggest that up to $10 \%$ of children with type 2 diabetes have antibodies and so could be classified as having latent autoimmune diabetes. ${ }^{40}$ The importance of this diagnosis is in the prediction of insulin requirement. It has been shown that GAD-65 positivity predicts an insulin requirement within three years. ${ }^{22}$

\section{DIABETES AND DISORDER (FIG 1, BOX C)}

This is intentionally a category that encompasses many different but rare diseases. Children in this category may be already under investigation for developmental delay or single organ pathology, or may have had treatment that could predispose to diabetes. These children may be assessed within several specialties without the different problems of the child being seen in the context of a single disorder. There are some classical presentations that should prompt consideration of specific disorders (table 2).

\section{Cystic fibrosis related diabetes (OMIM 219700)}

Cystic fibrosis related diabetes (CFRD) is the commonest form of secondary diabetes, and is becoming commoner with the improved life expectancy in cystic fibrosis. Diabetes is seen in up to $34 \%$ of children with cystic fibrosis. ${ }^{41}$ CFRD tends not to be associated with ketosis, presumably because of retained basal insulin secretion. Children with CFRD have increased hepatic glucose production which is less suppressed by insulin than in controls, ${ }^{42}$ and this is compounded by peripheral insulin resistance. ${ }^{43}$ One of the main problems with CFRD is that children are not usually symptomatic. Diabetes should be suspected in children with cystic fibrosis who show deterioration in lung function or body mass index without response to antibiotics. In the USA screening is by random glucose annually, followed by fasting glucose in those where the random glucose is greater than $7 \mathrm{mmol} / \mathrm{l}$, but more intensive screening may be justified..$^{44} 45$

Microangiopathic changes develop in CFRD with the improved survival. ${ }^{46}$ The development of CFRD is associated with worse outcome in cystic fibrosis, and early treatment with insulin can reverse the associated decline in lung function and body mass index. ${ }^{47}$ Most patients with CFRD are managed with insulin, but other hypoglycaemic agents are being trialled. For a more in depth review of diagnosis and treatment of CFRD the reader is referred to Mackie's excellent recent review. ${ }^{41}$ 


\begin{tabular}{|c|c|c|}
\hline Presentation & Diabetes type & Investigations \\
\hline $\begin{array}{l}\text { Overweight } \\
\text { May have ketoacidosis } \\
\text { Insulin dose }(<0.5 \text { units } / \mathrm{kg}) \\
+/ \text { - Acanthosis } \\
+ \text { / - Non-white }\end{array}$ & Type 2 & $\begin{array}{l}\text { OGT off insulin } \\
\text { GAD/IA-2 antibodies }\end{array}$ \\
\hline $\begin{array}{l}\text { Diabetes } \\
\text { Dominant family history } \\
\text { Usually lean } \\
\text { Usually no ketonuria }\end{array}$ & $\begin{array}{l}\text { MODY } \\
\text { HNF-1 } \alpha \\
\text { Glucokinase }\end{array}$ & Genetic analysis \\
\hline \multicolumn{3}{|l|}{ Neonatal diabetes } \\
\hline & $\begin{array}{l}\text { UPD } 6 \\
\text { Glucokinase } \\
\text { Pancreatic agenesis } \\
\text { Kir } 6.2 \text { mutations }\end{array}$ & $\begin{array}{l}\text { Genetic analysis } \\
\text { Genetic analysis } \\
\text { Ultrasound } \\
\text { Genetic analysis }\end{array}$ \\
\hline $\begin{array}{l}\text { Liver/renal impairment in diabetic child } \\
\text { and/or }\end{array}$ & Wolcott-Rallison & $x$ ray hips \\
\hline Cardiomyopathy & Alström & Ophthalmic and cardiac review \\
\hline Diabetes and visual impairment & $\begin{array}{l}\text { Alström } \\
\text { Wolfram } \\
\text { Bardet-Biedl }\end{array}$ & Ophthalmic review \\
\hline Deafness, diabetes, and family history & $\begin{array}{l}\text { Wolfram } \\
3243 \text { mitochondrial } \\
\text { mutation }\end{array}$ & $\begin{array}{l}\text { Ophthalmic review } \\
\text { Genetic analysis }\end{array}$ \\
\hline $\begin{array}{l}\text { Megaloblastic anaemia and diabetes } \\
+/- \text { hearing defect }\end{array}$ & Roger & $\begin{array}{l}\text { Hearing test } \\
\text { Trial of thiamine } \\
\text { Genetic analysis }\end{array}$ \\
\hline Short stature and diabetes & $\begin{array}{l}\text { Alström } \\
\text { Turner } \\
\text { Bardet-Biedl }\end{array}$ & $\begin{array}{l}\text { Ophthalmic and cardiac review } \\
\text { Karyotype } \\
\text { Ophthalmic review }\end{array}$ \\
\hline
\end{tabular}

\section{Down's syndrome diabetes}

There have been reports suggesting an increased risk of diabetes in Down's syndrome. ${ }^{48} 49$ Diabetes in Down's syndrome is autoimmune in origin and is similar to type 1 diabetes. Features that differ from type 1 diabetes are the earlier presentation of diabetes, and low prevalence of HLADR3 and HLA-DR4. ${ }^{50}$ Most children present acutely and treatment should be as for type 1 diabetes. Autoimmune thyroid and coeliac disease are more common in Down's syndrome patients with diabetes, than type 1 diabetes alone; guidelines for appropriate screening are available from the Down's syndrome medical interest group (www.dsmig. org.uk).

\section{Insulin resistance syndromes}

Insulin resistance syndromes can be thought of as a spectrum, with the metabolic syndrome at one extreme and severe life threatening disorders such as Rabson-Mendenhall at the other. Individuals may cross over between syndromes; so a girl may present with type 2 diabetes, then develop hypertension due to the metabolic syndrome, and later have problems with fertility due to polycystic ovarian syndrome.

\section{Polycystic ovarian syndrome}

Polycystic ovarian syndrome (PCOS) should be suspected in girls with menstrual disturbance, acne, and hirsutism. Ovarian cysts may not always be present, and raised testosterone and LH levels alone can be diagnostic. ${ }^{51}$ PCOS has increasingly been recognised as a disorder of insulin sensitivity. Metformin and other insulin sensitising agents have been used with success in adults with PCOS, to regulate the menstrual cycle. ${ }^{52}$ Metformin has been shown to be safe in adolescents with type 2 diabetes, ${ }^{29}$ and is therefore the preferred choice in PCOS. Recent evidence suggests that the use of metformin in girls with premature pubarche and hyperandrogenism at menarche can prevent the development of PCOS. ${ }^{53}$ Metformin should be used in conjunction with lifestyle modification, and treatment for dysmenorrhoea (for example, oral contraceptives) and hirsutism. ${ }^{52}$

\section{Other syndromes of insulin resistance}

Insulin resistance and diabetes are seen in lipodystrophy syndromes, and defects of the insulin receptor. Lipodystrophy syndromes range from severe neonatal diabetes to more subtle partial lipodystrophies, which may not present till adolescence. Donohue syndrome (previously known as leprechaunism) presents with severe intrauterine growth restriction, lipodystrophy, and fasting hypoglycaemia with postprandial hyperglycaemia. Most patients die within the first year. Rabson-Mendenhall syndrome is similar but with characteristic thickened nails and dental dysplasia. Patients have progressive diabetes and most die in the first decade. ${ }^{54}$ Type A syndrome affects lean, predominantly female adolescents with severe insulin resistance, hyperandrogenism, and acanthosis nigricans. Female patients have androgen excess ranging from mild hirsutism to frank virilisation. Diabetes or impaired glucose tolerance is one of the later manifestations of the disorder. ${ }^{55}{ }^{56}$ There is some evidence that metformin can be of use in type A insulin resistance. ${ }^{57}$

These rare insulin syndromes are discussed in more detail in Tritos and Mantzoros's comprehensive review. ${ }^{56}$

\section{Wolcott-Rallison syndrome (OMIM 226980)}

Wolcott-Rallison syndrome is a rare autosomal recessive condition characterised by extremely early onset diabetes, epiphyseal dysplasia, renal impairment, acute hepatic failure, and developmental delay. Non-autoimmune insulin deficient diabetes presents in infancy. ${ }^{58} 59$ The gene for 
Wolcott-Rallison has been isolated to EIF2AK3, a regulator of protein translation. ${ }^{59}$

\section{Wolfram syndrome (OMIM 222300)}

Wolfram syndrome (previously known as DIDMOAD) is an autosomal recessive syndrome, in which the association of diabetes with progressive optic atrophy under 16 years of age, is diagnostic. ${ }^{4}$ Other features, which appear with age, are sensorineural deafness, diabetes insipidus, dilated renal tracts, and truncal ataxia or more protean neurological signs. Non-autoimmune insulin deficient diabetes presents in the first decade. The median age of death is $30 .{ }^{60}$ Mutations in the Wolfram gene (WFS-1) are present in $90 \%$ of patients. ${ }^{61}$

\section{Alström syndrome (OMIM 203800)}

Alström syndrome is a rare autosomal recessive disorder characterised by short stature, early obesity, retinal degeneration, neurosensory deafness, infantile cardiomyopathy, chronic renal impairment, and diabetes mellitus. ${ }^{62}$ Hepatic involvement has been described. Visual and auditory impairment are progressive. Insulin resistant diabetes mellitus occurs in about $50 \%$ of patients with Alström syndrome and may respond to metformin, though most require insulin. ${ }^{62} 63$

\section{Bardet-Biedl syndrome (OMIM 209900)}

The key manifestations of Bardet-Biedl syndrome are retinal dystrophy, obesity, hand abnormalities, renal abnormality, and male hypogonadism; mental retardation may also be seen. Thirty per cent of patients develop insulin resistant diabetes. ${ }^{64}$ The syndrome is linked to seven loci, and inheritance seems to be variable, with some pedigrees showing recessive and some multigenic inheritance. ${ }^{65} 66$

\section{TRMA/Roger's syndrome (OMIM 249270)}

Thiamine responsive megaloblastic anaemia (TRMA) is the association of thiamine responsive megaloblastic anaemia with insulin deficient diabetes and sensorineural deafness. Diabetes may respond to thiamine, but all patients develop an insulin requirement in the long term. ${ }^{67}$ Mutations in SLC19A2 (a membrane bound thiamine transporter) cause this recessive disorder. ${ }^{68}$

\section{Mitochondrial mutations (OMIM 520000)}

In 1992 a mutation in mitochondrial DNA at nucleotide position 3243 was found to segregate with diabetes. ${ }^{69}$ This has proved to be the commonest mitochondrial mutation causing diabetes, but overall mitochondrial mutations are a rare cause of childhood diabetes. Factors that are suggestive of mitochondrial diabetes are maternal inheritance (as mitochondria are inherited exclusively from one's mother), ${ }^{70}$ and associated deafness, myopathy, or neurological deficits. Trials of specific treatments for mitochondrial diabetes have been unpromising, and patients usually require insulin from diagnosis. $^{70}$

\section{latrogenic diabetes \\ Thalassaemia}

Thalassaemia is associated with an increased incidence of insulin resistant diabetes. ${ }^{71}$ Hyperinsulinaemia is due to increased secretion of insulin as well as reduced extraction of insulin by the iron overloaded liver. The risk of diabetes is directly proportional to the number of transfusions, and increasing age. It is unknown whether this is due to iron related $\beta$ cell damage or $\beta$ cell exhaustion. ${ }^{72}$ Insulin resistance increases with puberty more in thalassaemic patients than in normal adolescents, and glycaemic control deteriorates. ${ }^{73}$ Adolescent thalassaemic patients should be made aware of the significance of polyuria and polydipsia as osmotic symptoms of diabetes.
Diabetes after transplantation

Glucose intolerance and overt diabetes have been increasingly recognised as sequelae of bone marrow transplantation. In a cohort of Finnish survivors $43 \%$ had diabetes or glucose intolerance $>3$ years after transplantation. ${ }^{74}$ These patients, who had received total body irradiation, appeared overweight and insulin resistant, compounded by hypogonadism causing insulin resistance in patients who have had cranial irradiation. $^{74}$

Post-transplant diabetes is a recognised complication of solid organ transplant in children with a prevalence of diabetes of $3-17 \%$ in renal and thoracic organ recipients. ${ }^{675}$ Risk factors for diabetes are use of tacrolimus immunosuppression, African ethnicity, and pulsed corticosteroid therapy. ${ }^{6}$

\section{Diabetes after steroid treatment}

Corticosteroids cause a rise in fasting insulin levels, an increased first phase insulin response, and increased hepatic glucose production. Diabetes is a recognised complication in about $20 \%$ of patients on high dose corticosteroids. ${ }^{76}$ Most healthy individuals will tolerate transient hyperglycaemia well during short courses of steroids, and may be managed by reduction in dietary sugar intake alone. Those with diabetes however, ${ }^{77}$ and their relatives ${ }^{78}$ may develop symptoms and require additional treatment.

\section{CONCLUSIONS}

The vast majority of children presenting with diabetes in the UK will have type 1 diabetes. The safest form of treatment for a newly presenting diabetic child is insulin, particularly if the child is unwell or has ketonuria. The well child with mild symptoms of diabetes is more problematic, but the balance of probabilities dictates that the overweight child from an ethnic minority is likely to have type 2 diabetes, and the slim white child is likely to have MODY, but there are non-obese, white type 2 patients and Asian MODY patients. It is important to review the diagnosis regularly if glycaemic control is difficult to achieve or other symptoms arise. It is vital to make an accurate diagnosis in these patients as the prognosis, management, impact on lifestyle, and surveillance for complications differ dramatically between the different subtypes of diabetes. Discussion with clinicians with particular interests in these less common forms of diabetes is recommended.

\section{ACKNOWLEDGEMENTS}

JP is a Diabetes UK clinical training fellow.

We would like to acknowledge the invaluable assistance of Professor Andrew Hattersley, Dr Sarah Ehtisham, and Dr Emma Gupta in the preparation of this review.

\section{Authors' affiliations}

J R Porter, T G Barrett, Institute of Child Health, Birmingham Children's Hospital, Steelhouse Lane, Birmingham B4 6NH, UK

\section{APPENDIX: WHERE TO GO FOR FURTHER INFORMATION}

- Dr T Barrett, Birmingham Children's Hospital; t.g.barrett@ bham.ac.uk

- Special interest in type 2 diabetes, Wolfram, TRMA, Wolcott-Rallison, Bardet-Biedl, Alström

- Prof. A Hattersley, Peninsula Medical School Exeter; a.t.hattersley@ex.ac.uk, www.diabetesgenes.org

- Special interest in MODY, mitochondrial disease, and ISPAD rare diabetes project 
- Dr S O'Rahilly, University of Cambridge; sorahill@ hgmp.mrc.ac.uk

- Special interest in insulin resistance syndromes

- Dr J Shield, University of Bristol; j.p.h.shield@Bristol. ac.uk

- Special interest in neonatal diabetes, Down's syndrome and diabetes, mitochondrial disease, obesity and type 2 diabetes

\section{REFERENCES}

1 Sperling M. Diabetes mellitus. In: Waldo N, eds. Nelson textbook of paediatrics. W.B.Saunders Company, 1996:1647.

2 World Health Organisation. Definition, diagnosis and classification of diabetes mellitus and its complications. Geneva: World Health Organisation, 1999.

3 Temple IK, Shield JP. Transient neonatal diabetes, a disorder of imprinting. Med Genet 2002;39:872-5.

4 Barrett TG, Bundey S, Macleod S. Neurodegeneration and diabetes: UK nationwide study of Wolfram (DIDMOAD) syndrome. Lancet 1995:346: 1458-63.

5 Hattersley AT, Turner RC, Permutt MA, et al. Linkage of type 2 diabetes to the glucokinase gene. Lancet 1992;339:1307-10.

6 Al-Uzri A, Stablein D, Cohn R. Posttransplant diabetes mellitus in pediatric renal transplant recipients: a report of the North American pediatric renal transplant cooperative study (NAPRTCS). Transplantation 2001;72:1020-4.

7 Ehtisham S, Barrett TG, Shaw NJ. Type 2 diabetes mellitus in UK children-an emerging problem. Diabet Med 2000;17:867-71.

8 Ehtisham S, Hattersley AT, Dunger DB, et al. First UK survey of paediatric type 2 diabetes and MODY. Arch Dis Child 2004;89:526-9.

9 Fagot-Campagna A, Pettitt DJ, Engelgau MM, et al. Type 2 diabetes among North American children and adolescents: an epidemiological review and public health perspective. J Pediatr 2000;136:664-72.

10 Reilly JJ, Dorosty AR. Epidemic of obesity in UK children. Lancet 1999;354:1874-5.

11 Muhammad BJ, Swift PG, Raymond NT, et al. Partial remission phase of diabetes in children younger than age 10 years. Arch Dis Child 1999;80:367-9.

12 Seissler J, de Sonnaville JJ, Morgenthaler NG, et al. Immunological heterogeneity in type 1 diabetes: presence of distinct autoantibody patterns in patients with acute onset and slowly progressive disease. Diabetologia 1998:41:891-7.

13 Borg H, Marcus C, Fernlund $P$, et al. Islet cell antibody frequency differs from that of glutamic acid decarboxylase antibodies/IA2 antibodies after diagnosis of diabetes. Acta Paediatr 2000;89:46-51.

14 Fida S, Myers M, Mackay IC et al. Antibodies to diabetes-associated autoantigens in Indian patients with type 1 diabetes: prevalence of antiICA512/IA2 and anti-SOX13. Diabetes Res Clin Pract 2001;52:205-11.

15 Umpierrez G, et al. Immunogenetic analysis suggests different pathogenesis for obese and lean African-Americans with diabetic ketoacidosis. Diabetes Care 1999;22:1517-23.

16 Batstra M, Petersen JS, Bruining GJ, et al. Low prevalence of GAD and IA-2 antibodies in schoolchildren from a village in the Southwestern section of the Netherlands. Hum Immunol 2001;62:1106-10.

17 American Diabetes Association. Type 2 diabetes in children and adolescents. Diabetes Care 2000;23:381-9.

18 Williams CL, Haynam LL, Daniels SR, et al. Cardiovascular health in childhood: A Statement for Health Professionals from the Committee on Atherosclerosis, Hypertension, and Obesity in the Young (AHOY) of the Council on Cardiovascular Disease in the Young, American Heart Association. Circulation 2002;106:143-60.

19 Drake AJ, Smith A, Betts PR, et al. Type 2 diabetes in obese white children. Arch Dis Child 2002;86:207-8.

20 Cole TJ, Bellizi MC, Flegal KM, et al. Establishing a standard definition for child overweight and obesity worldwide: international survey. BMJ 2000;320:1-6.

21 Arslanian S. Type 2 diabetes in children: clinical aspects and risk factors. Horm Res 2002;57(suppl 1):19-28.

22 Torn C, Landin-Olsson M, Ostman J, et al. Glutamic acid decarboxylase antibodies (GADA) is the most important factor for prediction of insulin therapy within 3 years in young adult diabetic patients not classified as type 1 diabetes on clinical grounds. Diabetes Metab Res Rev 2000;16:442-7.

23 Office of National Statistics. Census report 2001, ONS, 2001.

24 Wilkin TJ, Metcalf BS, Murphy MJ, et al. The relative contributions of birth weight, weight change, and current weight to insulin resistance in contemporary 5-year-olds: the EarlyBird Study. Diabetes 2002;51:3468-72.

25 Whincup PH, Gilg JA, Papacosta O, et al. Early evidence of ethnic differences in cardiovascular risk: cross sectional comparison of British South Asian and white children. BMJ 2002;324:635-40.

26 Henricsson $M$, Nystrom L, Blohme G, et al. The incidence of retinopathy 10 years after diagnosis in young adult people with diabetes: results from the nationwide population-based Diabetes Incidence Study in Sweden (DISS). Diabetes Care 2003;26:349-54.
27 Svensson M, Sundkvist G, Arnqvist HJ, et al. Signs of nephropathy may occur early in young adults with diabetes despite modern diabetes management: results from the nationwide population-based Diabetes Incidence Study in Sweden (DISS). Diabetes Care 2003:26:2903-9.

28 Stratton IM, Adler Al, Neil HA, et al. Association of glycaemia with macrovascular and microvascular complications of type 2 diabetes (UKPDS 35): prospective observational study. BMJ 2000;321:405-12.

29 Jones KL, Arslanian S, Peterokova VA, et al. Effect of metformin in pediatric patients with type 2 diabetes: a randomized controlled trial. Diabetes Care 2002;25:89-94.

30 Tattersall RB, Fajans SS. A difference between the inheritance of classical juvenile-onset and maturity-onset type diabetes of young people. Diabetes 1975;24:44-53.

31 Fajans SS, Bell GI, Polonsky KS. Molecular mechanisms and clinical pathophysiology of maturity-onset diabetes of the young. N Engl J Med 2001;345:971-80.

32 Edlund H. Transcribing pancreas. Diabetes 1998;47:1817-23.

33 Frayling TM, Evans JC, Bulman MP, et al. Beta-cell genes and diabetes: molecular and clinical characterization of mutations in transcription factors. Diabetes 2001;50(suppl 1):94-100.

34 Stride A, Hattersley AT. Different genes, different diabetes: lessons from maturity-onset diabetes of the young. Ann Med 2002;34:207-16.

35 Niolstad PR, Sovik O, Cuesta-Munoz A, et al. Neonatal diabetes mellitus due to complete glucokinase deficiency. N Engl J Med 2001;344:1588-92.

36 Klupa T, Warram JH, Antonellis A, et al. Determinants of the development of diabetes (maturity-onset diabetes of the young-3) in carriers of HNF-lalpha mutations: evidence for parent-of-origin effect. Diabetes Care 2002; 25:2292-301.

37 Stride A, Shepherd $M$, Frayling TM, et al. Intrauterine hyperglycemia is associated with an earlier diagnosis of diabetes in HNF-1 gene mutation carriers. Diabetes Care 2002;25:2287-91.

38 Pearson ER, Liddell WG, Shepherd $M$, et al. Sensitivity to sulphonylureas in patients with hepatocyte nuclear factor-1 alpha gene mutations: evidence for pharmacogenetics in diabetes. Diabet Med 2000;17:543-5.

39 Bingham C, Ellard S, Allen L, et al. Abnormal nephron development associated with a frameshift mutation in the transcription factor hepatocyte nuclear factor-1 beta. Kidney Int 2000:57:898-907.

40 Umpaichitra V, Banerji MA, Castells S. Autoantibodies in children with type 2 diabetes mellitus. J Pediatr Endocrinol Metab 2002;15(suppl 1):525-30.

41 Mackie AD, Thornton SJ, Edenborough FP. Cystic fibrosis-related diabetes. Diabet Med 2003;20:425-37.

42 Hardin DS, LeBlanc A, Para L, et al. Hepatic insulin resistance and defects in substrate utilization in cystic fibrosis. Diabetes 1999;48:1082-7.

43 Hardin DS, LeBlanc A, Lukenbough S, et al. Insulin resistance is associated with decreased clinical status in cystic fibrosis. J Pediatr 1997;130:948-56.

44 Moran A, Hardin D, Rodman D, et al. Diagnosis, screening and management of cystic fibrosis related diabetes mellitus: a consensus conference report. Diabetes Res Clin Pract 1999;45:61-73.

45 Lanng S, Thorsteinsson B, Nerup J, et al. Glucose tolerance in patients with cystic fibrosis: five year prospective study. BMJ 1995;311:655-9.

46 Sullivan MM, Denning CR. Diabetic microangiopathy in patients with cystic fibrosis. Pediatrics 1989;84:642-7.

47 Rolon MA, et al. Cystic fibrosis-related diabetes mellitus: clinical impact of prediabetes and effects of insulin therapy. Acta Paediatr 2001;90:860-7.

48 Anwar AJ, Walker JD, Frier BM. Type 1 diabetes mellitus and Down's syndrome: prevalence, management and diabetic complications. Diabet Med 1998;15:160-3.

49 Van Goor JC, Massa GG, Hirasing R. Increased incidence and prevalence of diabetes mellitus in Down's syndrome. Arch Dis Child 1997:77:186.

50 Shield J. Type 1 diabetes and other autoimmune disorders in Down's syndrome, Down's Syndrome Medical Interest Group (www.dsmig.org.uk), 2001

51 Homburg R. What is polycystic ovarian syndrome? A proposal for a consensus on the definition and diagnosis of polycystic ovarian syndrome. Hum Reprod 2002; 17:2495-9.

52 Pfeifer SM, Dayal M. Treatment of the adolescent patient with polycystic ovary syndrome. Obstet Gynecol Clin North Am 2003;30:337-52.

53 Ibanez L, Ferrer A, Ong K, et al. Insulin sensitization early after menarche prevents progression from precocious pubarche to polycystic ovary syndrome. $J$ Pediatr 2004;144:23-9.

54 Longo N, Wang Y, Smith SA, et al. Genotype-phenotype correlation in inherited severe insulin resistance. Hum Mol Genet 2002;11:1465-75.

55 Glaser NS. Non-insulin-dependent diabetes mellitus in childhood and adolescence. Pediatr Clin North Am 1997;44:307-37.

56 Tritos NA, Mantzoros CS. Clinical review 97: syndromes of severe insulin resistance. J Clin Endocrinol Metab 1998;83:3025-30.

57 Rique S, lbanez L, Marcos MV, et al. Effects of metformin on androgens and insulin concentrations in type $A$ insulin resistance syndrome. Diabetologia 2000;43:385-6.

58 Bin-Abbas B, Al-Muhim A, Al-Ashwal A. Wolcott-Rallison syndrome in two siblings with isolated central hypothyroidism. Am J Hum Genet 2002;111:187-90.

59 Delepine $M$, Nicolino M, Barrett T, et al. EIF2AK3, encoding translation initiation factor 2-alpha kinase 3, is mutated in patients with Wolcott-Rallison syndrome. Nat Genet 2000;25:406-9.

60 Khanim F, Kirk J, Latif F, et al. WFS1/Wolframin mutations, Wolfram syndrome and associated diseases. Hum Mutat 2001;17:357-67.

61 Strom T, Hortnagel K, Hofmann S, et al. Diabetes insipidus, diabetes mellitus, optic atrophy and deafness (DIDMOAD) caused by mutations in a novel gene (wolframin) coding for a predicted transmembrane protein. Hum Molec Genet 1998;7:2021-8. 
62 Russell-Eggitt IM, Clayton PT, Coffey R, et al. Alstrom syndrome. Report of 22 cases and literature review. Ophthalmology 1998;105:1274-80.

63 Satman I, Yilmaz MT, Gursoy N, et al. Evaluation of insulin resistant diabetes mellitus in Alstrom syndrome: a long-term prospective follow-up of three siblings. Diabetes Res Clin Pract 2002;56:189-96.

64 Green JS, Parfrey PS, Harnett JD, et al. The cardinal manifestations of BardetBiedl syndrome, a form of Laurence-Moon-Biedl syndrome. N Engl J Med 1989;321:1002-9.

65 Badano JL, Ansley SJ, Leitch CC, et al. Identification of a novel Bardet-Biedl syndrome protein, BBS7, that shares structural features with BBS1 and BBS2. Am J Hum Genet 2003;72:650-8.

66 Badano JL, Kim JC, Hoskins BE, et al. Heterozygous mutations in BBS1, BBS2 and BBS6 have a potential epistatic effect on Bardet-Biedl patients with two mutations at a second BBS locus. Hum Molec Genet 2003;12:1651-9.

67 Ozdemir M, Akcakus M, Kurtoglu S, et al. TRMA syndrome (thiamine responsive megaloblastic anemia): a case report and review of the literature. Pediatr Diabetes 2002;3:205-9.

68 Labay V, Raz T, Baron D, et al. Mutations in SLC19A2 cause thiamineresponsive megaloblastic anaemia associated with diabetes mellitus and deafness. Nat Genet 1999;22:300-4.

69 van den Ouweland JM, Lemkes HH, Ruitenbeek W, et al. Mutation in mitochondrial tRNA(Leu)(UUR) gene in a large pedigree with maternally transmitted type II diabetes mellitus and deafness. Nat Genet 1992;1:368-71.

70 Alcolado J, Laji K, Gill-Randall R. Maternal transmission of diabetes. Diabet Med 2002; 19:89-98.
71 Zuppinger K, Molinari B, Hirt A, et al. Increased risk of diabetes mellitus in beta-thalassemia major due to iron overload. Helvetica Paediatrica Acta 1979;34:197-207.

72 Dmochowski K, Finegood DT, Francombe W, et al. Factors determining glucose tolerance in patients with thalassemia major. J Clin Endocrinol Metab 1993;77:478-83.

73 Merkel PA, Simonson DC, Amiel SA, et al. Insulin resistance and hyperinsulinemia in patients with thalassemia major treated by hypertransfusion. N Engl J Med 1988;318:809-14.

74 Taskinen M, Saarinen-Pihkala UM, Hovi L, et al. Impaired glucose tolerance and dyslipidaemia as late effects after bone-marrow transplantation in childhood. Lancet 2000;356:993-7.

75 Paolillo J, Boyle GJ, Law YM, et al. Posttransplant diabetes mellitus in pediatric thoracic organ recipients receiving tacrolimus based immunosuppression. Transplantation 2001;71:252-6.

76 Ferner RE. Drug-induced diabetes. In: Alberti KGMM, eds. Bailliere's clinical endocrinology and metabolism. London: W. B. Saunders, 1992:849-66.

77 Feldman-Billard S, Lissak B, Benrabah R, et al. Intravenous pulse methylprednisolone therapy in eye disease: effect on glucose tolerance. Ophthalmology 2003;110:2369-71.

78 Henriksen JE, Alford F, Ward GM, et al. Risk and mechanism of dexamethasone-induced deterioration of glucose tolerance in non-diabetic first-degree relatives of NIDDM patients. Diabetologia 1997;40:1439-48.

79 Gloyn AL, Pearson ER, Antcliff JF, et al. Activating mutations in the gene encoding the ATP-sensitive potassium channel subunit Kir 6.2 and permanent neonatal diabetes. N Engl J Med 2004;350:1838-49.

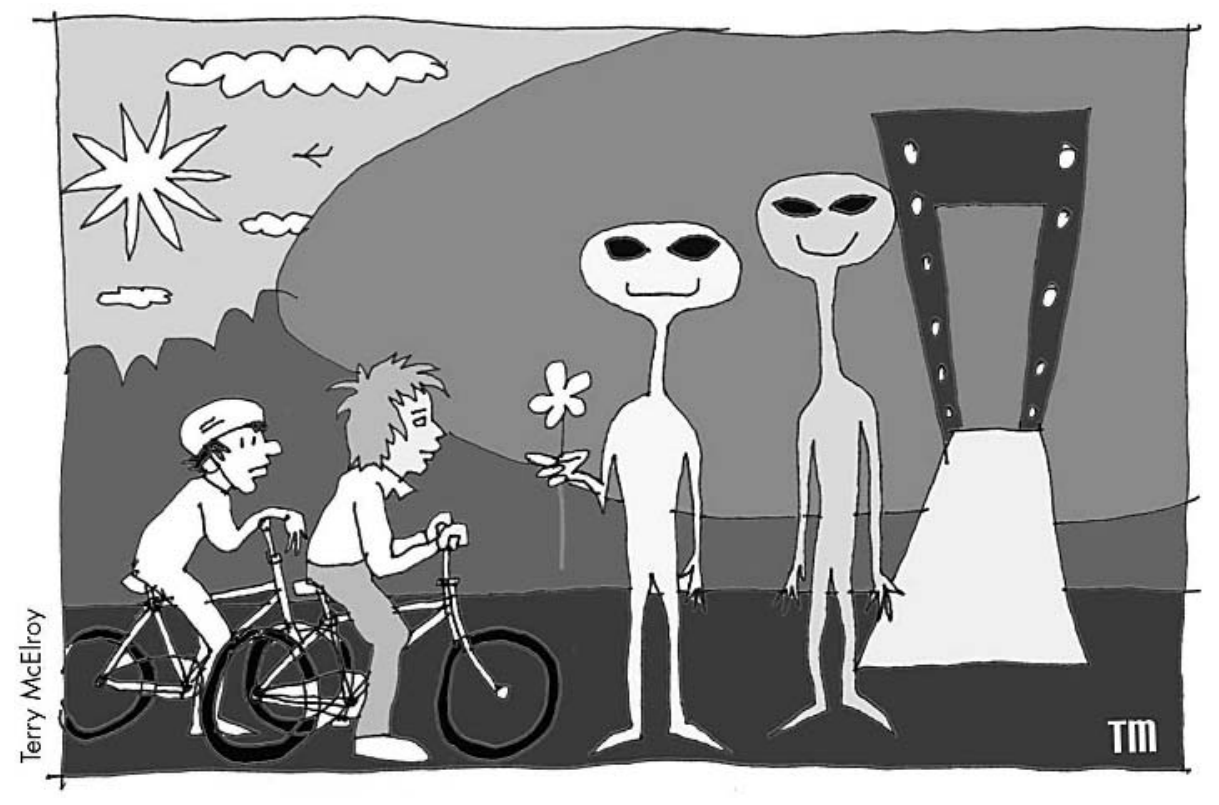

